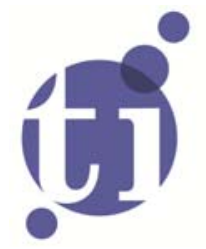

\title{
An Exploratory Landscape Metrics Approach to Agricultural Changes: Applications of Spatial Economic Consequences for the Algarve, Portugal
}

Eric de Noronha Vaz',2

Teresa de Noronha?

Peter Nijkamp3

1 Ryerson University, Toronto, Canada;

2 University of the Algarve, CIEO, Faro, Portugal;

3 Faculty of Economics and Business Administration, VU University Amsterdam, and Tinbergen Institute, The Netherlands. 
Tinbergen Institute is the graduate school and research institute in economics of Erasmus University Rotterdam, the University of Amsterdam and VU University Amsterdam.

More TI discussion papers can be downloaded at http://www.tinbergen.nl

Tinbergen Institute has two locations:

Tinbergen Institute Amsterdam

Gustav Mahlerplein 117

1082 MS Amsterdam

The Netherlands

Tel.: +31(0)205251600

Tinbergen Institute Rotterdam

Burg. Oudlaan 50

3062 PA Rotterdam

The Netherlands

Tel.: +31(0)10 4088900

Fax: $+31(0) 104089031$

Duisenberg school of finance is a collaboration of the Dutch financial sector and universities, with the ambition to support innovative research and offer top quality academic education in core areas of finance.

DSF research papers can be downloaded at: http://www.dsf.nl/

Duisenberg school of finance

Gustav Mahlerplein 117

1082 MS Amsterdam

The Netherlands

Tel.: +31(0)20 5258579 


\title{
An Exploratory Landscape Metrics Approach to Agricultural Changes: Applications of Spatial Economic Consequences for the Algarve, Portugal
}

\author{
Eric de Noronha Vaz ${ }^{1,2}$, Teresa de Noronha ${ }^{2}$, Peter Nijkamp ${ }^{3 *}$ \\ * Tinbergen Institute, The Netherlands
}

\begin{abstract}
Socio-economic growth and urban change have been an increasing concern for decision makers in recent decades. Led by the creation of new infrastructures to support economic activity, periurban areas have mostly become adversely affected and the consequences for the ecological but also the rural landscape have become a lasting concern. The monitoring and mapping of land-use change, especially in areas where urban change has been high, is crucial. The collision between traditional economic activities related to agriculture in tourist areas such as the Algarve and current demand for tourism infrastructures in urban regions is also leading to loss of economic activity. This paper uses a combined Geographical Information System approach with remotesensing imagery and land cover databases to perform a Markov analysis for the purpose of quantifying changes in agricultural areas. The paper then expands on the nature of the agricultural changes observed, and offers a multi-temporal assessment by means of landscape metrics in order to understand the shifting land-use patterns for the Algarve in land use planning and regional economic equilibrium: (1) forest regions become transformed into agricultural areas and agricultural areas become urban; (2) areas which are initially agricultural become scattered residential regions created by economic investors; and (3) changes in the land-use have a cyclical nature in which in the course of the economic recession we may witness a shift in this effect brought about a decrease in tourism and focus on traditional sectors.
\end{abstract}

Keywords: land use change, markov transition matrix, landscape metrics, agricultural land loss Pn577evtn

\footnotetext{
${ }^{1}$ Ryerson University, Department of Geography, Toronto, Canada

${ }^{2}$ University of the Algarve, CIEO, Faro, Portugal

${ }^{3}$ VU University, Faculty of Business and Economics, Amsterdam, the Netherlands
} 


\section{Introduction}

While urban areas have become a cradle for economic growth, on the other hand, urbanization processes do not necessarily signify economic prosperity and growth (Henderson, 2003). These processes have also been shown to be associated with important considerations concerning the sustainability of urban regions and their carrying capacity (Rees and Wackernagel, 1996) and the degradation of the traditional historical identity of the landscape (Antrop, 2005), due to excessive and often uncontrolled economic and population dynamics. Urban areas are, in fact, directly linked to socio-economic dynamics, and city growth has allowed a great number of industries and businesses to prosper. New markets emerging within the urban regions have highlighted the importance of cities as an organized and structured entity, designed to cope with our needs, demands and the generation of social values. A city, as such, is a proportionally growing output of population growth and economic change (Boserup, 2005). The economic impact of urban growth has led to fundamental questions related to the environmental sustainability (Campbell, 1996; Giddings et al., 2002) that cities offer, and to whether urban settlements currently offer the best solution for future economic and ecological stability in view of their unprecedented anthropogenic costs at the spatial level (Deal and Schunk, 2004). While the future expansion of urban regions and continued sprawl is adversely affecting our environment and natural rural landscapes (Gar-On Yeh and Li, 1999), the sectors of activity that determine the form of the city are undermining the most sustainable options, given the demands of certain sectors of activity. This has led to a greater occurrence of leapfrogging ${ }^{1}$ (Heim, 2001), loss of agricultural land (Fazal, 2000) and an increase in commercial, industrial and complex patterns in urban-rural environments (McDonnell et al., 1997). Decision making is however, influenced by the need to make a choice that articulates the consequences not only for economic growth but also for the planning and infrastructures of the city. While urban sprawl leads to the amelioration of certain aspects of the urban environment, artificial land-use types tend to concentrate, causing severe consequences for ecosystems and the existence of less profitable land use and land cover types (Alberti, 2008). This is especially felt at the local and regional level, where changes in the land-use patches often lead to severe ecological imbalances (Zipperer et al., 2012). As land use has a specific externality function given the region's economic output (Alessio, 1973), urban regions are changing and undergroup spatial land transitions that allow the demands of economic growth to be supported (Fujita, 1976). However, from an evolutionary perspective, the dynamics of land use have become much more complex than traditional CobbDouglas function estimates (Goldberger, 1968). In this sense, novel assessment methods are often possible at desktop level (Batty, 1998), and allow much more elaborate land-use transitions to be tracked over time and assessed than those proposed in neoclassical economies. Agricultural land for instance, becomes scarce in areas where a service sector is more predominant, while urban regions tend to swallow up agricultural land that does not seem to be relevant for the production function of the positive externality of the city. These concepts of combined and often compatible land use dynamics are lost in traditional economic visions, where the diagnosis of the ecological spectrum of spatial impacts often fails at different administrative levels, hindering the possibility of local and regional analysis. However, from an evolutionary perspective, an appreciation of the complexity of these relationships over space (Frenken and Boschma, 2007) allows us to gain a better understanding of anthropogenic influences in the face of irremediable

\footnotetext{
${ }^{1}$ Leapfrogging' occurs when developers reject expensive city centre sites in favo of cheaper land on the periphery of cities, or beyond the 'Green Belt'
} 
changes: for instance (i) soil properties are changed irreversibly; (ii) historical and unique characteristics of the landscape become forever lost; (iii) biodiversity and ecological equilibrium in the area stagnates (Eppink et al., 2004). While more sustainable options should be considered, the economic crisis offers the possibility for the conceptual rethinking of economic paradigms based on downscaling, such as the restriction (Schneider et al., 2010) of the growth of urban regions, and local agricultural production could offer the prospect of some renewed equilibrium through coevolution with the ecological and socio-economic systems (Saifi and Drake, 2008), avoiding excessive pressure on the landscape and reducing the need for excessive land consumption (Kallis, 2011). In this sense, land-use change models allow impacts to be assessed by means of an integrative scenario-based approach, in particular in regions with similar geographical and regional characteristics (Bajocco et al., 2012). The current consequences of the economic crisis observed in southern Europe, provide, in some sense, a unique opportunity at the regional level to assess spatial changes, while accepting the past impacts and to promote a more eco-friendly and sustainable future. The CORINE Land Cover (CLC) data set is a useful tool to assess land use changes for Europe since the early 1990s. The CLC survey, started on the 27 June 1985, as a programme that would address the following issues: the state of individual environments; the geographical distribution and the state of natural areas; the geographical distribution and abundance of wild fauna and flora; the quality and abundance of water resources; the type of land cover structure and the state of the soil; the quantities of toxic substances discharged into environments; and a list of natural hazards (EEA, 1995). In this respect the CLC survey can be seen as an 'an experimental project for gathering, coordinating and ensuring the consistency of information on the state of the environment and natural resources in the Community' (85/338/EEC, Council Decision 27/6/1985). Furthermore, it may be seen as an important data source to measure by means of a Geographical Information System (GIS), specific land use for Europe, and view this information from a temporal perspective, given that the CLC survey is currently in its third round. The existence of three rounds, called CLC 90, CLC 2000, and CLC 2006, enable a multi-temporal projection of path-tendencies of land use change between CLC 90 to CLC 2000, and accurate assessments of the predicted results for CLC 2006. If the model can provide holds an interesting interpretation of what the land-use changes were (e.g. adapted through stochastic models) it becomes possible to project our land-cover change to a future time. The integration of non-linear methodologies or more spatially-clear frameworks to model land use transitions, allows GIS to become a valuable tool to assess landuse change, as well as to identify what are the necessary future responses that decision making may give to mitigate the impacts of land-use change in general. These methodologies have been widely accepted in the framework of urban growth models, where land-use changes are measured in terms of multi-temporal changes in urban areas over series sets of temporal frames. These spatio-temporal changes are however, not limited only to urban growth modeling, but, much more than this, may be used to create change matrices that show the consequences of the rate of registered land use change for other land use types, such as forest areas, agriculture, wetland systems, vegetation types, and other land-cover categories, ranging from a more specific land use type to a more coarse level, depending on whether the analysis output deals with results concerning local, regional or international land uses. The combination of this information with existing national data makes it possible to have a complex decision system where land use change may be analysed and assessed using in a GIS. The use of the Reserva Agrícola Nacional (RAN) for Portugal is a good example of a national repository dealing with agricultural land for Portugal. The RAN has become a tool for territorial management, covering those areas that, due 
to their morphological, climatic and social conditions, are most suitable and have the greatest potential for the development of agricultural activities. Essentially, the areas contained within the RAN are those which are more fertile, but many, have a greater tendency to be converted to urban use. However, local patterns of agricultural activity, typical in the rural areas of the Algarve have lost their traditional positive externalities, leading to the augmentation of negative externalities brought by non-systemic production sectors. This led in 1976 to the "Law of Landuse” (Decreto Lei n. 794/76, 5th November), which brought urban development control policies, and the forecasting of agricultural activity. However, urban and population pressure, as well as the current concentration on the secondary and tertiary sector threaten the sustainability of agricultural land, and increase urbanization and agricultural abandonment in Portugal. The present study: (1) provides a combined analysis of the impacts of agricultural land changes in the RAN; (2) and demonstrates the link that tourism growth has had on these changes. While tourism does provide an interesting opportunity for economic growth, it is fundamentally important to integrate tourism within the traditional agricultural activities of regions, in order to avoid future change that might bring irreversible adverse consequences, from a spatial perspective, for the land, and even for economic growth.

\section{Study area}

The southernmost region of Portugal is called the Algarve, which has a total size of $5412 \mathrm{~km}^{2}$. Nowadays, it is one of the most well-known regions, given its prosperous tourist sector. The region has a unique wetland landscape (Vaz et al., 2012a), and a rich historical past dating back to the Roman civilization. The Algarve (Figure 1) is the region of Portugal, which has the most Moorish influence. It is thus well endowed with the artistry of the Roman, Moorish and Christian civilizations.

The influences of these different cultures on the environment have led to a distinct architectural landscape, but also to a unique type of ecological landscape, formed by anthropocentric activity since antiquity, and current economic growth generated by the mass tourism industry. It is therefore an ecological landscape of contrasts, which is protected in the continental network of conservation habitats (79/409/CEE). The Algarve consists of three quite distinct regions: Interior, Barrocal, and Litoral. In the Algarve there is a marked asymmetry between the Interior (located on the northern part of the region) and the Litoral (the coastal area of the Algarve). It is within the coastal area that the land tends to be more fertile, and converging ecosystems in the south-east area together create the Reserva Natural da Ria Formosa, known for its many different types of edaphic species. With most of its southern area being part of the NATURA network, the Algarve has an interesting combination of agricultural land and wetland systems (Vaz et al., 2012b). The synergy between both these elements provides the region with rich biodiversity, appreciated by many birdwatchers and tourists worldwide. Close to these wetland systems, sandy beaches extend along the coast of almost the entire region, and have been successfully exploited since the 1970s, changing a transition economy led by the rural agricultural sector into an urban service sector, where infrastructures have been built mainly to support tourism demand and economic growth. According to the 2009 Census, the Algarve had an estimated population estimate of 450485 in 2010. Faro, the district capital, has one of the three major airports, and the region is divided into 16 municipalities and two zones on either side of the the municipality of Loulé: the Barlavento (in the east of the Algarve) and the Sotavento (in the west of the Algarve). 


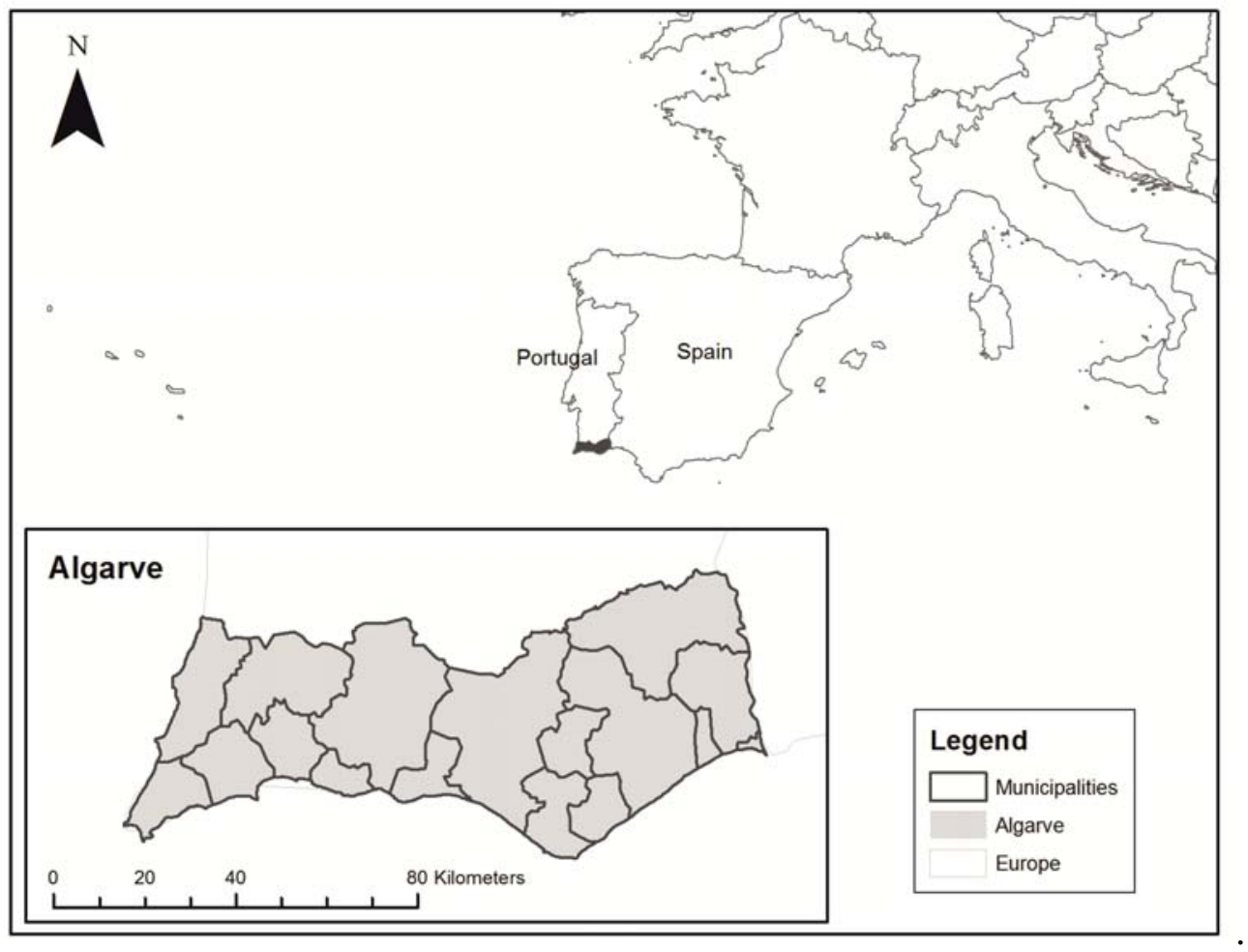

Figure 1 - Location of the Algarve in Europe and administrative municipality divisions

\section{Materials and Methods}

\subsection{Materials}

\section{CORINE Land Cover}

The Corine Land Cover (CLC) survey presently in its third round, constitutes a highly important data set for understanding land-use changes and transitions at the European level. The project itself began in 1985, with a particular purpose as a tool to address the state of and changes witnessed at a spatially-explicit level in the environment, under a common agenda of reporting the issue of natural hazards concerning toxic substances and their impacts on fauna and flora (EEA, 1995). What started out as an experimental project in the 1990s has grown into a spatial database containing a land-use inventory for the entire European Union, where a multi-temporal understanding of land-use changes has become possible since its second round in 2002, called CORINE Land Cover 2000. The succeeding round, CLC 2006, allowed for a more complex multi-temporal analysis. The complexity added, given a third moment in time, is strongly linked to the capabilities of manipulating and calibrating the results of scenarios based on the two preceding land covers, in an attempt to model with more accuracy the land-use dynamics in 2006. In its third round, the CLC survey has thus become an indispensable tool for future landuse modelling based on a scenario and speculative approach with regards to future possible changes in the socio-economic, natural, and anthropogenic environment at local, regional, but and European level. 


\section{Reserva Agrícola Nacional}

The Reserva Agrícola Nacional (RAN) is a Portuguese tool for land management, which covers those areas which, an account of their favourable morphological, climatic and social conditions, are considered to have the greatest potential for the development of agricultural activities. Essentially, the areas included within the RAN are more fertile, and, thus, would be a serious loss if appropriated for urban areas. Nevertheless, local patterns of agricultural activity, typical of the rural areas of the Algarve, have lost some of their traditional positive externalities, leading to an increase in negative externalities generated by non-systemic production sectors. As already explained in the Introduction, this led in 1976 to the "Land-use Law" (Decreto Lei n. 794/76, 5th November), which brought policies for urban development control, and the planning of agricultural activity. However, urban and population pressure, as well as the existing concentration on the secondary and the tertiary sector, have led to further agricultural abandonment, and inevitable urban growth in Portugal. A special framework of legislation was conceived in 1982, which expressed the concerns about agricultural land loss, and thus the RAN (Decreto Lei n. 451/82, 16th November) was created, with the main objective of recovering lost agricultural and abandoned land and protecting vulnerable agricultural areas. The RAN is divided in two distinct classes (A and B), based on physical and geographical characteristics (Decreto Lei n. 196/89, 14th June). RAN land is systematically decreasing, while urban areas are registering a steady increase (Vaz et al., 2011c).

\subsection{Methods}

\subsubsection{Regional Geographic Information System}

The implementation of a Geographic Information System (GIS) is crucial to manipulate and understand spatially-explicit data in a multi-temporal environment: in particular, the integration of regional characteristics reflected in the spatial dimension of land use transitions, in particular concerning non-sustainable land use choices (Peña et al., 2007), as well as allowing both the creation of regional response systems to assess the adaptive capacity of land and the collection of information on the typology of the land-use changes observed (Verburg et al., 2010). The incorporation of socio-economic, natural, and administrative data in such a system permits: different criteria, to be assessed using integrative multi-criteria evaluation techniques (Jankowski, 1995); the handling and manipulation of results, in order to make a better decisions about the best preventive measures in the short, medium, and long run; and the possibility to progress as a legitimate scientific field in its own right (Wright et al., 2004). The functional and applied capabilities of a GIS can provide data handling solutions possible at desktop level, which also facilitate decision making at more precise spatial scales, leading to advances in other decision making tools, for example concerning transportation systems (O'Sullivan et al., 2000). For the Algarve, the administrative boundaries were used in order to form subsets of the available data sets of the CORINE Land Cover survey and the RAN. The embedded information in a vector polygon shapefile, allows data to be aggregated and edited in a georeferenced manner, thus adding to the local and regional importance of visualizing the results derived by the provision of spatial information. In the case of the Algarve, this corresponded to a complete data set of 16 municipalities, and the integration of agricultural land changes from the RAN inventory, as well as the integration of two timeframes (1990 and 2006) from the CORINE Land 
Cover survey at administrative level. The different land use classes were then converted into a grid format, allowing more advanced spatial calculations to be processed in order to compare both the effects of the transition of land use changes in time and the additional spatial dynamics over the entire region.

\subsubsection{Landscape Metrics}

The advantage of landscape metrics for analyzing agricultural and socio-economic changes is strongly linked to the possibility of understanding the geomorphological and topologic transitions observed from a quantitative description of the often complex and heterogeneous dynamics of land use (Antrop and Van Eetvelde, 2000). In this analysis the extension and typologies of different areas are considered, forming a functional land use mosaic allowing the assessment of diverse quantifiable patterns, regarding the composition of the landscape as well as its configuration (Farina, 2006). These distinct dimensions have an effect not only on a discrete spatial surface such as an entire region and contribute to understanding the fragmentation of existing habitats (Hargis et al., 1998), but are also extremely effective when related to established administrative boundaries, where there is the possibility of assessing different land use consequences, given that different socio-economic and policy actions have been implemented over time. This is spatially expressed by quantification relating the diversity of land use, the areas with a specific type of land use per administrative territory, the morphology of the shape of the land cover and its control with respect to the total proportion of land use within a specific administrative boundary. Comparison of the distinct results at the administrative level, allows their assessment to be facilitated within the regional geographic information system (RGIS). For local and regional decision making, this is of the utmost importance, as it allows an explanatory framework of the registered land-use changes to be developed, while maintaining a consistent spatial dimension at the administrative level, and understanding which subsets of landuse have changed, and what may be expected in the future. This supports a socio-economic analysis of land-use change at the spatial level, having enabled the identification of phenomena such as loss of agricultural land to urbanization in recent decades in the Algarve, and permitted the RGIS to have not only analytical capabilities with regard to of regional change in land use, but also visual possibilities for rapid assessment and result sharing. Several spatial statistical analyses were conducted to understand the changes in land use and the consequences for agriculture. The clear difference between the interior of the Algarve and the rapid changes witnessed in the littoral region, led us to assume that there would be some effects on agricultural land use, in particular given the changes registered in the RAN.

\subsubsection{Shannon's Diversity Index and spatial auto-correlation}

A Shannon's Diversity Index (SDI) was generated at the administrative level. In this sense, SDI provides a definition of 'variety', that is, the existence of different types of land use within an administrative boundary. The richness of the patches existing at the municipal level, permits us to understand whether there have been significant changes over time in the land use and land cover. The total diversity is calculated at the level of each cell as follows: 


$$
\mathrm{H}^{\prime}=\sum_{i=1}^{S}\left[\left(\frac{n_{i}}{n}\right) \ln \left(\frac{n_{i}}{n}\right)\right]
$$

Where $n_{i}$ represents the number of patches within to the administrative boundary and $n$ is the total number of land-use classes found there. The calculation of this index allowed the richness of the diversity of different land use types to be evaluated. A predominant increase in diversity was evident throughout the years concerning this landscape analysis with the exception of a decrease in the diversity of patches for Alcoutim, Aljezur and Vila do Bispo (Table 1). In a visual assessment, rural areas reported a lower SDI while the coastal region, in particular the more urbanized areas, showed more change in the SDI. At the spatial level this shows clear evidence of the loss of certain agricultural land types.

Table 1: Variation in Shannon’s Diversity Index between 1990 and 2006

\begin{tabular}{|l|r|r|c|}
\hline Municipality & $\mathbf{1 9 9 0}$ & \multicolumn{1}{|c|}{$\mathbf{2 0 0 6}$} & Variation in SDI \\
\hline Albufeira & 1.77 & 1.96 & 0.19 \\
\hline Alcoutim & 1.6 & 1.56 & -0.04 \\
\hline Aljezur & 2.02 & 2.01 & -0.01 \\
\hline Castro Marim & 1.91 & 2.12 & 0.21 \\
\hline Faro & 2.21 & 2.32 & 0.11 \\
\hline Lagoa & 1.94 & 2.34 & 0.4 \\
\hline Lagos & 2.31 & 2.39 & 0.08 \\
\hline Loule & 2.11 & 2.26 & 0.15 \\
\hline Monchique & 1.28 & 1.34 & 0.06 \\
\hline Olhao & 2.16 & 2.36 & 0.2 \\
\hline Portimao & 2.47 & 2.6 & 0.13 \\
\hline SB Alportel & 1.47 & 1.61 & 0.14 \\
\hline Silves & 2.16 & 2.19 & 0.03 \\
\hline Tavira & 1.9 & 2.05 & 0.15 \\
\hline Vila do Bispo & 2.1 & 2.06 & -0.04 \\
\hline VRSA & 2.41 & 2.48 & 0.07 \\
\hline
\end{tabular}

\subsubsection{Total landscape changes and their impact on agricultural land use, when adapting to Sustainable Tourism}

Total changes in the landscape were calculated by means of studying the distribution of changes in patches at cell level. The total changes in patches corresponded to a percentage value of the difference between the two years per main class. An increase of urban land of 50.2 per cent had occurred over the preceding decades, while simultaneously 94.88 per cent of total agricultural land was lost. This overwhelming loss of agricultural land was also found to have direct spatial 
repercussions in terms of the increase of the total forest cover of 47.03 per cent between 1990 and 2006. The changes in agricultural land (Figure 2) suggests an alarming scenario, particularly given the variations in the geomorphological and landscape characteristics of these areas, and the steady increase still being observed in new urban surfaces. A closer look at administrative level shows that the regions of most agricultural variation are predominantly more urban and located along the Algarve coast where tourism is abundant. The combination of these results with the RAN clarifies that there is not only an underlying pattern of increased agricultural land loss, but also a predominant tendency to use this land for urban activities hand in hand with agricultural abandonment. At the economic level these results tend to be quite dire, as one of the main advantages of the region is its scenic beauty and ecological landscapes. The high concentration of NATURA 2000 sites in this area is witness to the ecological importance of these landscapes, and presents a unique opportunity for sustainable tourism. One of the main advantages resides in the adaptive properties of sustainable tourism (Hunter, 1997). The spatial analysis performed with landscape metrics, in line with adaptive strategies for sustainable tourism, also indicates the importance of using the wetland systems of the Algarve as a unique ecological tourism resource. Wetland systems are one of the most productive regions of the world, with unique breeding grounds and habitats for marine species and in particular, marine birds. Given, in general, the low structural changes of most of the wetland systems at present, a unique cluster for birdwatching tourism could be fostered. In line with measures to combat the economic recession, the existing landscapes and natural biodiversity of these tourism types, allied to traditional sectors of agricultural activity, as well as to the unique landscape characteristics of the Algarve, could allow tourism in the Algarve to be reshaped without compromising a sustainable future. The application of spatial information, in particular landscape metrics, suggest that the agricultural land and wetland systems currently at risk, present a unique economic opportunity for economic activity that does not cause excessive urbanization or environmental degradation contrary to what is happening in traditional Tourism sectors.

\section{Discussion and explanation underlying causes of landscape changes}

The increasing agricultural land loss described above is explained the ever increasing tendency to of use this land for urban activities, as well as by the unusually fast rapid of the agricultural sector, leading to a transformation of the agricultural landscapes in Western Europe (Meeus, 1993). These combined phenomena put at risk not only the Algarve's traditional heritage (Vaz et al., 2012c) but also its environmental ecological equilibrium (Newton and Mudge, 2003), therefore the underlying causes should be further investigated, and combined with quantitative methods borrowed from landscape ecology (Riitters et al., 1995) and economic rationale, complemented with integrating spatial methodologies. In general, the Western economic growth pattern is characterized by a slow decline of many agricultural activities which, having become more mechanized and intensive, reduce labour and, eventually, the share of rural areas used exclusively for agricultural purposes. Such areas are frequently located on the peripheries of small cities and, nowadays, include new functions characteristic of the modern urban world, such as new tourist activities (rural tourism, festivals, traditional production, local arts, exploration of archeological sites, and so on). 


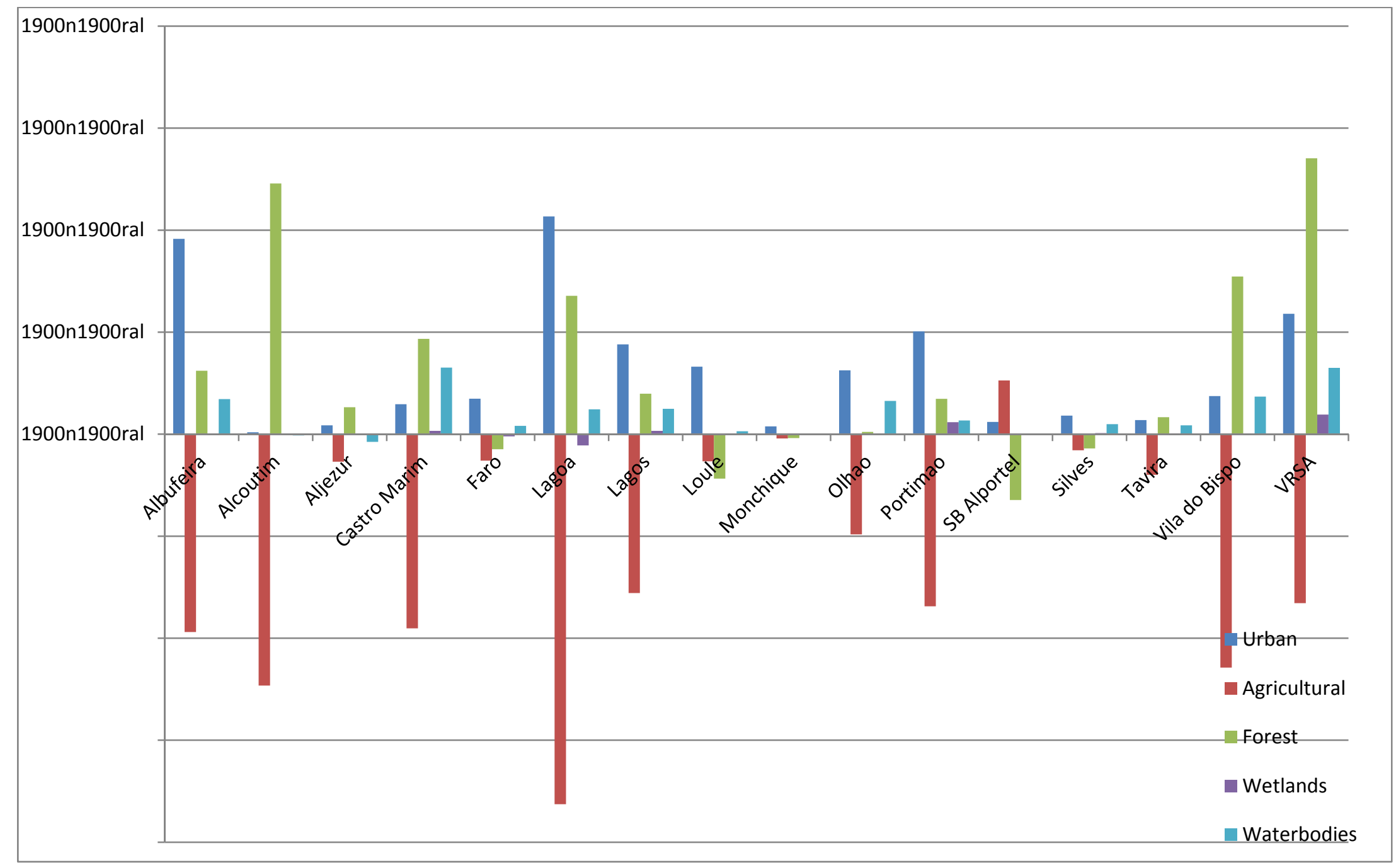

Figure 2 - Transitions of land-use classes per Municipality 1990-2006 
In Portugal, however, the data show a drastic increase in the loss of agricultural land, which is being replaced by forestry and urban constructions. In our view, at least, three distinct factors have contributed to this: 1) the unusually large extent of protected areas, defined by land-use regulation, result in an artificial pressure on the rest of the territory. Such a situation generates artificially increasing land prices, including in agricultural areas which have in many cases become residential quarters or have been used to locate public facilities; 2) Population increases, which have imposed a permanent growth of urban areas, often in the form of urban sprawl; and finally, 3) the rapidly decreasing importance of most of the agro-food activities (both agriculture and the food industry) as active participants in the regional economic activities. A more detailed overview of each of these factors helps to better understand the results of the previous section:

1) One of the reasons for the strict legislation defining so many protected areas is to safeguard land from the invasive nature of mass tourism. However, such rigid decision may have brought perverse results: The Algarve has three quarters of its territory classified as protected areas, under one of the following classifications: RAN, REN, Rede Natura and Área Protegida.

Figure 3 shows that, with the exception of Alcoutim and Vila Real de Santo António, all the municipalities have more than half of their surface classified as a protected area, eight of them having about 80 per cent of the land under such legislative restrictions (Aljezur, Faro, Olhão, Monchique, São Brás de Alportel, Silves, Tavira e Vila do Bispo). All together, only about a quarter of the Algarve area does not impose limitations of any kind on construction and urban growth. Considering that the Algarve registered the second highest growth rate in the country it should be questioned whether this policy has served to contain urban growth and urban sprawl and whether public agents can succeed in resisting he strong pressures that tourism and related activities have imposed. Most probably, they have been able to overcome such restrictions, by finding out legal ambiguities, and facilitating more flexibility to serve economic and political interests. What is certain is the continuous rise of property prices up to excessively high levels. As expected, in the current economic crisis, these strongly speculative prices led to a sudden crash, with a severe impact on regional investment and growth. The severe impact has additionaly been felt mainly by existing obsolete infrastructures whose functionality has diminished as tourist demand has substantially shortened. Meanwhile, infrastructures are becoming abandoned leading to additional constrain on regional environmental system, with high ecological value and where sounder specialized agricultural productions used to be present in decades prior to the construction and mass tourism.

2) The permanent growth of urban areas, also in the form of urban sprawl, is the next factor which needs to be explained. The region shows that land used for urban purposes increased at a speed significantly above the average for all the Portuguese regions. In fact, in terms of the rate of change, the extent of the urbanized area more than doubled between 1990 and 2006. This picture of growth is reinforced by examining the built-up urban area as a proportion of the total surface. In 16 years, this share has risen from 1.9 per cent to 3.9 per cent. The continuous urban space represents only $0.1 \%$ of the all region, similarly to the rest of the country as a whole. While, between 1990 and 2000, its growth rate was significant it then decreased between 2000 and 2006, in line with the latest developments for Portugal as a whole.

On the other hand, between 1990 and 2000, the discontinuous urban growth in the Algarve region has increased faster than that in mainland Portugal as a whole, but it slowed down between 2000 and 2006, indicating less dispersion in the evolution of the urban built-up areas for 
that period, compared with the situation in Portugal as a whole. Thus development is in ine with the strategy advocated in the PROT Algarve (Plano Regional de Ordernamento do Territorio), to increase the scale of the regional urban system, through the development of agglomariation economies.

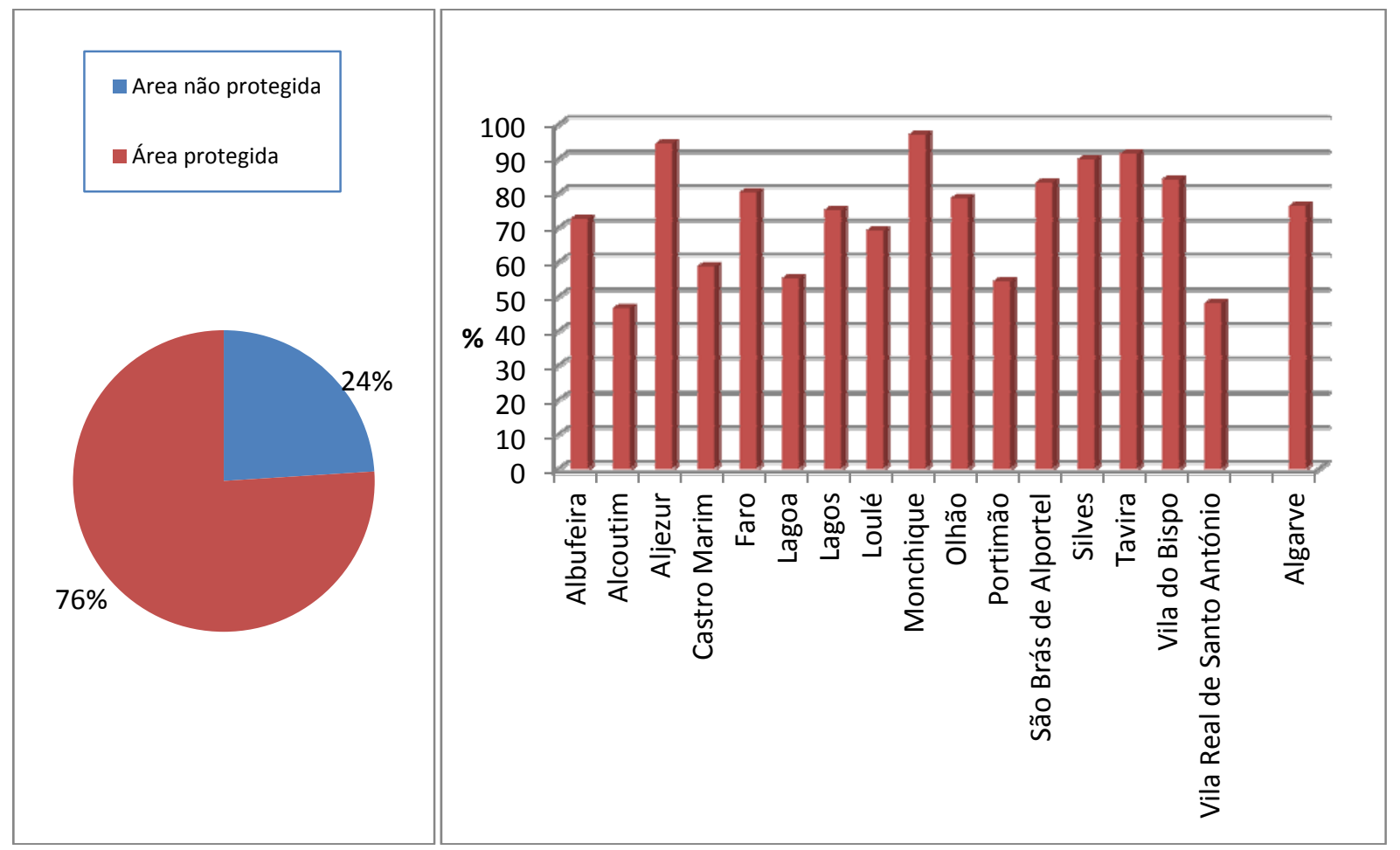

Source: CAOP e SIG CCDR Algarve

Figure 3 - Protected areas in Algarve

The Algarve also has a special position in relation to the land occupied by sports and lisure. More than a quarter of the area occupied by sports and leisure in Portugal as a whole is found in the Algarve. It is also significant that, in 1990 the land devoted to sports and leisure represented 0.5 per cent of the territory of the region, rising to 0.8 per cent in 2000 , and reaching 1.3 per cent in 2006. These calculated values contrast with the 0.1 per cent growth recorded for mainland Portugal as a whole in 2006. This rapid development recorded in the Algarve for the 16-year period 1990-2006, confirms a growth of developed areas (urban land used for sports and leisure) of 2.5 times. The proportion of land occupied by sports and leisure in the Algarve is a disproportionally large share (1.3 per cent) of the land occupied by these activities in mainland Portugal as a whole (4 per cent). The Algarve's substantial share is explained by the very high concentration of golf courses in the region.

3) The fast decreasing importance of most of the agro-food activities (both agriculture and food industry) as active participants of the regional economic activities is the last factor to be considered. Traditionally, and because of its a mild and sunny climate, the Algarve has centered its extensive agricultural productions mostly in citrus fruit, almonds, olives and wine. Besides 
this, it also produced intensively and frequently under partial hydroponic conditions other horticultural products such as early season strawberries. However, throughout the last few decades the production level has decreased. This was mainly the cause distribution channels no longer pass through local channels, as they are determined by multinational firms whose acquisition interests are based on the price-quantity bargaining abilities of their partners. Most of the small or medium-sized farms producing traditional agricultural products face increasing difficulties in following the distribution requirements of big farms, and do not have the necessary capacity to capture any sort of market share. With increasing labour prices determined by the demand of the tourism sector, farmers have faced huge pressure from increasing costs and market quota reductions: land abandonment has been the only alternative for most of them.

\section{Conclusions}

Landscape metrics have mostly been applied to landscape ecology. However, the main rationale for the landscape metrics has predominantly been the research interest in tracking changes in biodiversity and natural habitats. Little attention has been given so far to the combination of regional support systems and socioeconomic change in the light of landscape metrics applied to the anthropogenic environment. The anthropogenic environment is, however, strikingly complex, and understanding the interactions at land use level, especially taking in consideration the effects at the administrative level, also, allows the understanding of both a subset of policies that mitigate the risk of losing fragile environment and what are the best economic options for a sustainable future. This paper has shown that landscape metrics can be used to understand from an economic perspective the loss of agricultural land in the Algarve to the mass tourism industry. The increase of agricultural land loss, albeit as a result of strong legislative controls, indicates that economic growth is leading to unhealthy effects on the anthropogenic ecological landscape. The differences between the economies of the North of the region and the South are selfexplanatory, and lead to the conclusion that restrictive strategies should be applied in more urban areas, by fostering support systems for traditional agricultural productions and implementing new tourism opportunities such as sustainable tourism. The Algarve as a unique region of Europe, faces the same challenges as most anthropogenic environments: a conflict between excessive economic growth, loss of sustainable areas, and decision making for sustainable development. A combination of Geographic Information Systems at the regional level combined and landscape metrics approaches allows these problems to be tackled more successfully aid in particular enables the quantification of these issues over space, permitting advanced spatiotemporal analysis, which may help decision makers to initiate more appropriate actions for sustainable economic growth.

\section{References}

Alberti, M. (2008). Advances in Urban Ecology: Integrating Humans and Ecological Processes in Urban Ecosystems (Springer).

Alessio, F.J. (1973). A Neo-Classical Land Use Model: The Influence of Externalities. The Swedish Journal of Economics 75, 414-419. 
Antrop, M. (2005). Why landscapes of the past are important for the future. Landscape and Urban Planning 70, 21-34.

Antrop, M., and Van Eetvelde, V. (2000). Holistic aspects of suburban landscapes: visual image interpretation and landscape metrics. Landscape and Urban Planning 50, 43-58.

Bajocco, S., De Angelis, A., Perini, L., Ferrara, A., and Salvati, L. (2012). The Impact of Land Use/Land Cover Changes on Land Degradation Dynamics: A Mediterranean Case Study. Environmental Management 49, 980-989.

Batty, M. (1998). Urban evolution on the desktop: simulation with the use of extended cellular automata. Environment and Planning A 30, 1943-1967.

Boserup, E. (2005). The Conditions of Agricultural Growth: The Economics of Agrarian Change Under Population Pressure (Aldine).

Campbell, S. (1996). Green Cities, Growing Cities, Just Cities?: Urban Planning and the Contradictions of Sustainable Development. Journal of the American Planning Association 62, 296-312.

Deal, B., and Schunk, D. (2004). Spatial dynamic modeling and urban land use transformation: a simulation approach to assessing the costs of urban sprawl. Ecological Economics 51, 79-95.

EEA. (1995). CORINE Land Cover. EEA report. http://www.eea.europa.eu/ publications/COR0landcover (consulted on 05.08.09)

Eppink, F.V., van den Bergh, J.C.J.M., and Rietveld, P. (2004). Modelling biodiversity and land use: urban growth, agriculture and nature in a wetland area. Ecological Economics 51, 201-216.

Farina, A. (2006). Principles and Methods in Landscape Ecology: Toward a Science of Landscape (Springer).

Fazal, S. (2000). Urban Expansion and Loss of Agricultural Land - a GIS Based Study of Saharanpur City, India. Environment and Urbanization 12, 133-149.

Frenken, K., and Boschma, R.A. (2007). A Theoretical Framework for Evolutionary Economic Geography: Industrial Dynamics and Urban Growth as a Branching Process. J Econ Geogr 7, 635-649.

Fujita, M. (1976). Spatial patterns of urban growth: Optimum and market. Journal of Urban Economics 3, 209-241.

Gar-On Yeh, A., and Li, X. (1999). Economic Development and Agricultural Land Loss in the Pearl River Delta, China. Habitat International 23, 373-390.

Giddings, B., Hopwood, B., and O’Brien, G. (2002). Environment, economy and society: fitting them together into sustainable development. Sustainable Development 10, 187-196. 
Goldberger, A.S. (1968). The Interpretation and Estimation of Cobb-Douglas Functions. Econometrica 36, 464-472.

Hargis, C.D., Bissonette, J.A., and David, J.L. (1998). The behavior of landscape metrics commonly used in the study of habitat fragmentation. Landscape Ecology 13, 167-186.

Heim, C.E. (2001). Leapfrogging, Urban Sprawl, and Growth Management: Phoenix, 19502000. American Journal of Economics and Sociology 60, 245-283.

Henderson, V. (2003). The Urbanization Process and Economic Growth: The So-What Question. Journal of Economic Growth 8, 47-71.

Hunter, C. (1997). Sustainable tourism as an adaptive paradigm. Annals of Tourism Research 24, 850-867.

Jankowski, P. (1995). Integrating geographical information systems and multiple criteria decision-making methods. International Journal of Geographical Information Systems 9, 251273.

Kallis, G. (2011). In defence of degrowth. Ecological Economics 70, 873-880.

McDonnell, M.J., Pickett, S.T.A., Groffman, P., Bohlen, P., Pouyat, R.V., Zipperer, W.C., Parmelee, R.W., Carreiro, M.M., and Medley, K. (1997). Ecosystem processes along an urbanto-rural gradient. Urban Ecosystems 1, 21-36.

Meeus, J.H.A. (1993). The transformation of agricultural landscapes in Western Europe. Science of The Total Environment 129, 171-190.

Newton, A., and Mudge, S.M. (2003). Temperature and salinity regimes in a shallow, mesotidal lagoon, the Ria Formosa, Portugal. Estuarine, Coastal and Shelf Science 57, 73-85.

O’Sullivan, D., Morrison, A., and Shearer, J. (2000). Using desktop GIS for the investigation of accessibility by public transport: an isochrone approach. International Journal of Geographical Information Science 14, 85-104.

Peña, J., Bonet, A., Bellot, J., Sánchez, J.R., Eisenhuth, D., Hallett, S., and Aledo, A. (2007). Driving Forces Of Land-Use Change in a Cultural Landscape Of Spain. In Modelling Land-Use Change, E. Koomen, J. Stillwell, A. Bakema, and H.J. Scholten, eds. (Springer Netherlands), pp. $97-115$.

Riitters, K.H., O’Neill, R.V., Hunsaker, C.T., Wickham, J.D., Yankee, D.H., Timmins, S.P., Jones, K.B., and Jackson, B.L. (1995). A factor analysis of landscape pattern and structure metrics. Landscape Ecology 10, 23-39.

Saifi, B., and Drake, L. (2008). A coevolutionary model for promoting agricultural sustainability. Ecological Economics 65, 24-34. 
Schneider, F., Kallis, G., and Martinez-Alier, J. (2010). Crisis or opportunity? Economic degrowth for social equity and ecological sustainability. Introduction to this Special Issue. Journal of Cleaner Production 18, 511-518.

Vaz, E., Walczynska, A., and Nijkamp, P. (2012a) Regional challenges in tourist wetland systems: an integrated approach to the Ria Formosa in the Algarve, Portugal. Regional Environmental Change, DOI:10.1007/s10113-012-0310-9

Vaz, E., Noronha, T., and Nijkamp, P. (2012b). The use of gravity concepts for agricultural landuse dynamics: a case study on the Algarve. International Journal of Foresight and Innovation Policy 8, 262-271.

Vaz, E., Cabral, P., Caetano, M., Nijkamp, P., and Painho, M. (2012c). Urban heritage endangerment at the interface of future cities and past heritage: A spatial vulnerability assessment. Habitat International 36, 287-294.

Verburg, P., van Berkel, D., van Doorn, A., van Eupen, M., and van den Heiligenberg, H. (2010). Trajectories of land use change in Europe: a model-based exploration of rural futures. Landscape Ecology 25, 217-232.

Wright, D.J., Goodchild, M.F., and Proctor, J.D. (2004). Demystifying the Persistent Ambiguity of GIS as "Tool” versus "Science.”Annals of the Association of American Geographers 87, 346362.

Zipperer, W., Foresman, T., Walker, S., and Daniel, C. (2012). Ecological consequences of fragmentation and deforestation in an urban landscape: a case study. Urban Ecosystems, DOI: 10.1007/s11252-012-0238-3 